\title{
ASSESSMENT OF SURGICAL LIP REPOSITIONING FOR TREATMENT OF EXCESSIVE GINGIVAL DISPLAY - A ONE YEAR FOLLOW UP STUDY
}

\author{
Noury A Abdelkafe*, Bahaa eldin A. Tawfik ${ }^{* *}$
}

\begin{abstract}
Objective: The present study was performed to evaluate the success rate of the lip repositioning surgery by assessment of the soft tissue changes and the relapse associated with that procedure. Methods: six female patients were included in the study who suffered from gummy smile ranging from 4-6 $\mathrm{mm}$ due to hypermobility of the upper lip or short upper lip. Pre-operative measurement of the amount of gingival display during smiling was recorded digitally using Adobe Photoshop cs6 through well standardized photographs. Lip repositioning surgery was performed under local anesthesia for all patients by removing a strap of epithelium through an elliptical outline followed by primary closure of the wound by interrupted 0-5 resorbable suture. All patients were followed up at 14 days, 4 months, 8 months and 12 months, postoperative assessment was done by measuring the same preoperative measurement. Results: Post-operative measurements at 14 days follow up, showed marked reduction in the gingival display. However complete relapse was observed at 4 month and thereafter. Conclusion: Lip repositioning surgery isn't an effective technique in addressing excess gingival display with almost complete relapse associated with the procedure.
\end{abstract}

\section{INTRODUCTION}

Excessive gingival display which is more commonly known as gummy smile is a condition where there is an overexposure of the gingiva during smiling. It is characterized by showing more than $2-3 \mathrm{~mm}$ of the gingiva ${ }^{(1)}$ however, the amount of discrepancy to be considered unattractive varies between different populations, gender and age. It is agreed worldwide that excess of more than $3 \mathrm{~mm}$ is considered to be unattractive ${ }^{(2-4)}$. Many modalities have been advocated to restore the dentogingival relation for the management of gummy smile those of which includes; crown lengthening procedures $^{(5)}$, orthodontic leveling of the gingival margins of maxillary teeth ${ }^{(6)}$, intrusion of the upper teeth ${ }^{(7)}$, orthognathic surgery(8), botulinum toxin injections ${ }^{(9)}$ and lip repositioning surgery ${ }^{(10)}$.
Lip repositioning procedure was first described by Rubinstein and Kostianovsky ${ }^{(1)}$ as a part of medical plastic surgery in 1973; later on the original technique was modified by Rosenblatt and Simon ${ }^{(12)}$ in 2006 and was introduced in the field of dentistry.

The surgery is a conservative technique for treatment of gummy smile and is thought to be of a permanent effect where the aim of the surgery is to limit the smile muscle pull by shortening the depth of the upper vestibule ${ }^{(13)}$. Many modifications have been introduced to the original procedure over time ${ }^{(14-16)}$ and several studies have showed that the technique along with its modifications to be successful. There is little standardized information for clinicians to make informed decisions when choosing this technique for the treatment of gummy smile. From here comes the necessity for our study

* Dentist, The National institute of Neuromotor System.

** Assistant Professor, Department of Oral and Maxillofacial Surgery, Faculty of Dental Medicine (Boys), Al-Azhar University, Cairo, Egypt. 
to evaluate the lip repositioning surgery and the amount of relapse associated with the procedure and when does it happen through a well-designed study using fixed parameters. Through this we can reach the level of scientific evidence and fulfilling the basics for evidence-based dentistry.

\section{PATIENTS AND METHODS}

Six patients aged from $25-35$ years with the chief complaint of a gummy smile presented to the outpatient clinic of Oral and Maxillofacial Surgery Department, Faculty of Dental Medicine, Al-Azhar University, Boys, Cairo. Past as well as present medical and dental history were taken from all patients, also the extraoral examination of the lip architecture was done followed by intraoral examination which includes; gingival health in terms of the width of the attached gingiva, oral mucosa, periodontium and teeth. The study involved patients with upper lip hypermobility, short upper lip and gummy smile which ranges from $4-6 \mathrm{~mm}$. On the other hand, patients with vertical maxillary excess, insufficient width of attached gingiva, smokers and non-healthy patients were excluded from the study. The normal upper lip length ranges from $20-24$ $\mathrm{mm}^{(17)}$ so measuring the upper lip length at rest were performed by recording the vertical distance from the subanal to the stomion point by a millimeter ruler in addition to measuring the amount of incisor show at rest in order to diagnose the short upper lip ( normal incisal show at rest1 $-4 \mathrm{~mm}$ ), while upper lip hypermobility was diagnosed by measuring the amount of translation of the upper lip from rest to maximum smiling if it exceeded the normal range by half or double the amount, then diagnosis of hypermobility was confirmed (normal amount of translation is $6-8 \mathrm{~mm}$ ) ${ }^{(18)}$. Lateral cephalometric $\mathrm{x}$-ray was obtained for all patients to exclude vertical maxillary excess, extra and intraoral photographs were taken for assessment, planning and records. Preoperative assessment included measuring the amount of gingival display during smiling digitally using Adobe Photoshop Cs6 through a standardized photographs, this was performed by measuring the vertical length from the free gingival margin of the upper central incisor to the base of the upper lips

\section{Ethical considerations}

The research objectives were explained to the patients in details and an informed consent was signed by all patients before starting treatment.

\section{Surgical procedure}

Adequate local anesthesia was obtained through a bilateral infraorbital block with local infiltration at the labial vestibule. The technique consists of creating an elliptical incision in the depth of the vestibule. An indelible marker was used to mark the borders of the elliptical incision. The inferior border of the incision was placed at the mucogingival junction and was extended from the mesial aspect of the first premolars bilaterally, superior border of the incision was placed above and parallel to the inferior one at a distance double the amount of gingival display. Partial thickness incisions were made using a No.15 scalpel across the superior and inferior borders. The outlined mucosa was removed by sharp dissection leaving the underlying connective tissue exposed. The first suture was placed at the area of frenectomy to ensure symmetry and proper midline placement while the remaining closure bilaterally was completed with interrupted sutures using a 5-0 resorbable suture.

\section{Postoperative instructions \& follow up}

All patients were dismissed with verbal and informed instructions on avoiding any manipulation or mechanical trauma to the surgery and to minimize lip movements when smiling or talking as much as possible. They were also instructed to apply ice packs at 20-minute intervals for 24 hours and soft diet during the first postoperative week. Postoperative medications included; analgesics were prescribed for 3 days, anti-inflammatory was prescribed 3 times 
a day for 1 week and antibiotics were prescribed 12 hourlies for 1 week to help in reducing pain, swelling and edema and to prevent infection. Sutures were removed after 2 weeks; patients were followed up at the following periods; 14 days after the procedure, 4 months, 8 months and 12 months. Post-operative measurements of the amount of gingival display at smiling were recorded in each follow up interval.

\section{RESULTS}

All patients reported pain that was tolerable and controlled with analgesics, swelling and upper lip edema was also reported which subsided within a week. None of the patients reported paresthesia or any serious complications. Sutures were removed after two weeks where a scar line was observed at the new proposed vestibular position which was obtained by the surgery. Results showed that there was a remarkable decrease in the gingival display at the $14^{\text {th }}$ day after treatment, this change was statistically significant, however, at 4,8 \& 12 months there was a marked increase in the gingival display to reach the same values as baseline.

TABLE (1): Measurements of gingival exposure pre and post lip repositioning surgery

\begin{tabular}{|c|c|c|c|c|c|}
\hline Case No. & $\begin{array}{c}\text { Pre-operative } \\
\text { measurements }(\mathrm{mm})\end{array}$ & 14 days $(\mathrm{mm})$ & 4 months $(\mathrm{mm})$ & 8 months $(\mathrm{mm})$ & $12 \mathrm{months}(\mathrm{mm})$ \\
\hline 1 & 5.33 & 0 & 5.2 & 5.33 & 5.33 \\
\hline 2 & 4.2 & 0 & 4.2 & 4.2 & 4.2 \\
\hline 3 & 4 & 0 & 4 & 6 & 6 \\
\hline 4 & 6 & 0 & 4.94 & 5.12 & 5.12 \\
\hline 5 & 5.12 & 0 & 4.82 & 4.82 & 4.82 \\
\hline 6 & 4.82 & 0 & & 4 & 4 \\
\hline
\end{tabular}

\section{DISCUSSION}

The aim of this study was to describe the lip repositioning surgery as a method of decreasing gummy smile in a conservative way, due to the fact that this technique is considered to be shorter and have fewer postoperative complications compared to the orthognathic surgery ${ }^{(19)}$ but on the other hand its success rate and possible outcomes not to mention the associated relapse remains under investigations.

Excessive gingival display may be due to different etiologies which could be skeletal, dentoalveolar, soft tissue dependent or multifactorial, each of those previously mentioned causes have its own line of treatment. The scientific literature contains many case reports of different treatment modalities for EGD correction ${ }^{(20,21)}$. Patients with vertical maxillary excess are not good candidate for lip repositioning surgery, thus it's contraindicated for them, where the best line of treatment for those types of patients is the orthognathic surgery ${ }^{(19)}$. On the other hand, inadequate attached gingiva in the anterior maxillary region may possess difficulties in the flap design, stabilization and suturing therefore increase the amount of relapse, so lip repositioning surgery is contraindicated in those patients as well ${ }^{(22)}$.

As mentioned before due to the lack of studies about the success rate, soft tissue changes and relapse associated with the lip repositioning surgery, thus the main goal of our study was to assess the previously mentioned items through 
well standardized techniques where all parameters were fixed during the whole follow up period'

Digital methods are more reliable because its avoids the errors associated with obtaining the measurements clinically only thus affecting the accuracy of the results, this can be explained due to the fact that it would be impossible to put the ruler at the exact same points every time the measurements were being taken at each follow up interval, moreover, the placement of the ruler against the soft tissue of the lip will lead to compressibility of those tissues causing more distension and pressure in the area of interest giving inaccurate readings. This may also explain why many previous researches ${ }^{(24-26)}$ about lip repositioning may have presented in-accurate results about the success rate of the procedure as they depended on clinical means for their measurements in addition to other factors such as; short term follows up, neglecting the soft tissue changes by measuring fixed parameters and the small number of patients included in the study.

At 14 days after the procedure, marked decrease in the amount of gingival display was noticed, we have also to emphasize that there was an obvious increase in the vermillion length of the upper lip such a change was highly appreciated by the patient and were previously observed in other studies ${ }^{(2,23)}$, this change can be more described as if the patient had a filler injection in her upper lip, unfortunately this change didn't persist, at 4 month follow up and thereafter, complete relapse was observes

\section{CONCLUSION}

Lip repositioning surgery is not a technique with a lasting result in reducing gummy smile from $4-6$ $\mathrm{mm}$ and doesn't provide a permanent effect not to mention that the improvement is only seen in the first 2 weeks post-operatively and may persist up to 1 month maximum but with an inevitable relapse thereafter, in other words relapse is un-avoidable.

\section{REFERENCES}

1. Silberberg N, Goldstein M, Smidt A. Excessive gingival display: etiology, diagnosis, and treatment modalities Quintessence Int 2009; 40:809-18.

2. Gabric Panduric D, Blaskovic M, Brozovic J, Susic M Surgical treatment of excessive gingival display using lip repositioning technique and laser gingivectomy as an alternative to orthognathic surgery. J Oral Maxillofac Surg. 2014; 72:4041-4051

3. Tawfik OK, El-Nahass HE, Shipman P, Looney SW, Cutler $\mathrm{CW}$, Brunner M. Lip repositioning for the treatment of excessive gingival display: A systematic review. J Esthet Restor Dent. 2018; 30:101-112.

4. Ribeiro-Junior NV, Campos TV, Rodrigues JG, Martins TM, Silva CO. Treatment of excessive gingival display using a modified lip repositioning technique. Int J Period Restorative Dent. 2013; 33:309-31

5. Passos L, Soares FP, Gallo M. Esthetic rehabilitation through crown lengthening surgery and conservative CAD/CAM veneers: A multidisciplinary case report. Case Rep Dent. 2016; 2016:5720851.

6. Uzuka S, Chae MJ, Tai K, Tsuchimochi T, Park HJ. Adult gummy smile correction with temporary skeletal anchorage devices. World J Orthod. 2018;7(1):34-46.

7. Lahoti E, Choudhury PP, Nakib AA, Kumar M. Correction of gummy smile in a patient of vertical maxillary excess using absolute anchorage system. APOS Trends Orthod. 2018; 8:44-8. s

8. Nishiyama A, Ibaragi S, Yoshioka N, Shimo T, Sasaki A. A case of maxillary protrusion and gummy smile treated by multi-segmental horseshoe le fort I osteotomy. Int J Oral Maxillofac Surg. 2017;46(1):327

9. Mostafa D. A successful management of severe gummy smile using gingivectomy and botulinum toxin injection: A case report. Int J Surg Case Rep. 2018; 42:169-174.

10. KD, Yadalam U, Ranjan R, Narayan SJ. Lip repositioning, an alternative treatment of gummy smile - A case report. J Oral Biol Craniofac Res. 2018; 8(3):231-233.

11. Rubinstein AM, Kostianovsky AS. Cosmetic surgery for the malformation of the laugh: Original technique in Spanish. Prensa Med Argent. 1973; 60:952.

12. Rosenblatt A, Simon Z. Lip repositioning for reduction of excessive gingival display: A clinical report. Int J Periodontics Restorative Dent. 2006; 26:433-7. 
13. Farista S, Yeltiwar R, Kalakonda B, Thakare KS. Laserassisted lip repositioning surgery: Novel approach to treat gummy smile. J Indian Soc Periodontol. 2017;21(2):164-168.

14. Alammar A, Heshmeh O, Mounajjed R, Goodson M, Hamadah O. A comparison between modified and conventional surgical techniques for surgical lip repositioning in the management of the gummy smile. J Esthet Restor Dent. 2018;9.

15. Alammar AM, Heshmeh OA. Lip repositioning with a myotomy of the elevator muscles for the management of a gummy smile. Dent Med Probl. 2018;55(3):241-246.

16. Sanchez IM, Gaud-Quintana S, Stern JK. Modified lip repositioning with esthetic crown lengthening: A combined approach to treating excessive gingival display. Int J Periodontics Restorative Dent. 2017;37(1): e130-e134.

17. Peck S, Peck L, Kataja M. The gingival smile angles. Angle Orthodo 1992; 62:91-100.

18. Silva CO, Ribeiro-Junior NV, Campos TV, Rodrigues JG, Tatakis DN. Excessive gingival display: treatment by a modified lip repositioning technique. J Clin Periodontol. 2013; 40:260-265

19. Humayun N, Kolhatkar S, Souiyas J, Bhola M. Mucosal coronally positioned flap for the management of excessive gingival display in the presence of hypermobility of the upper lip and vertical maxillary excess: a case report. J Periodontol. 2010; 81:858-63.

20. Gupta KK, Srivastava A, Singhal R, Srivastava S. An innovative cosmetic technique called lip repositioning. J Indian Soc Periodontol. 2010;14(4):266-269.

21. Simon Z, Rosenblatt A, Dorfman W. Eliminating a gummy smile with surgical lip repositioning. J Cosmetic Dent. 2007;23(1):102-109.

22. Abdullah W, Khalil H, Alhindi M, Marzook H. Modifying gummy smile: a minimally invasive approach. J Contemp Dent Pract. 2014;15(6):821-826.

23. Rao AG, Koganti VP, Prabhakar AK, Soni S. Modified lip repositioning: A surgical approach to treat the gummy smile. J Indian Soc Periodontol. 2015;19(3):356-9.

24. Muthukumar S, Natarajan S, Madhankumar S, Sampathkumar J. Lip repositioning surgery for correction of excessive gingival display. J Pharma Bioallied Sci. 2015; 7(2):794-6.

25. Jananni M, Sivaramakrishnan, Libby JT. Surgical correction of excessive gingival display in class I vertical maxillary excess: Mucosal strip technique. 2014;5(2):494-98.

26. Ambrosio F, Gadalla H, Kapoor N, Neely LA, Kinaia MB Surgical lip repositioning procedure to correct excessive gingival display: A case report of identical twins. Clin Adv Periodontics. 2018;8(2):48-53. 